Corresponding Author:

Inês Marcelino

ines.vr@hotmail.com

Received: 7 January 2020

Accepted: 21 April 2020

Published: 3 May 2020

Publishing services provided by

Knowledge E

(c) Inês Marcelino and João. Lanzinha. This article is

distributed under the terms of the Creative Commons

Attribution License, which permits unrestricted use and redistribution provided that the original author and source are credited.

Selection and Peer-review under the responsibility of the STARTCON19 Conference Committee.

\section{Proposal of Methodology for Technical Inspection and Rehabilitation Intervention for Multi-family Building of the 60's in Portugal}

\section{Inês Marcelino1 and João. Lanzinha²}

${ }^{1}$ Civil Engineer, Universidade da Beira Interior, Calçada Fonte do Lameiro, Edifício II Engenharia, 6200-001 Covilhã, Portugal

${ }^{2}$ Universidade da Beira Interior, C-made - Centre of Materials and Building Technologies, LABSED Ubimedical, Calçada Fonte do Lameiro, Edifício II Engenharia, 6200-001 Covilhã, Portugal

\section{Abstract}

The rehabilitation of old buildings has been increasing over the last few years due to the lack of maintenance and there is an advanced degradation of the Portuguese built park. This sector of the civil construction has as objective the full reutilization of the existing buildings maintaining its identity. Since Portugal has a large percentage of buildings where it is possible to identify constructive times that accompanied the implementation of different trends and technological evolutions, defining differentiated strategies for intervention. The 1960s deserve some prominence in Portugal because it is composed of a significant set of buildings with reticulated structure in reinforced concrete and without concerns from the point of view of thermal behaviour, which are now inhabited mainly by elderly people, often residing alone.

The following work aims to present a methodology proposal and apply it to a case study. The proposed methodology includes the detailed inspection of a building from the 60s in Covilhã, the consultation of residents and the definition of intervention proposals based on the main nonconformities detected. In the first stage, a detailed analysis of the existing situation is proposed, which includes a technical inspection report on the common parts and the different fractions of the building and a survey of residents in order to know their opinions and expectations regarding the work to be carried out. In the second phase we propose a set of measurements, the realization thermograms and the thermal analysis of the different habitable fractions of the building based on the current thermal regulation. After analysing all the data collected, the intervention proposals are defined according to the needs of the building and the residents, in a phased way and with the aim of creating better accessibility, comfort and use conditions. 


\section{Introduction}

The Portuguese built park presents an advanced state of degradation, with growing needs for intervention and to contribute to combat depopulation, especially in historic centres.

According to the 2011 Censuses, there are 965,782 buildings in need of intervention, of which 156.09 (46.8\%) belong to the decade of 60's. The 60's deserve some prominence in Portugal because it marks the beginning of the construction with reticulated structure in reinforced concrete and is composed by a significant set of buildings in that times without concern from the point of view of the thermal behaviour [1].

\section{Proposal of Inspection Methodology}

\subsection{Some existing methodologies in Portugal}

In this work it is intended to present a proposal of a methodology for inspection of existing buildings, based on a bibliography already published and the direct application to a case study. In Portugal, despite the lack of maintenance of buildings, there is still no official and mandatory method of technical inspection of buildings. According to the website of the City Hall of Lisbon, in 2012 it was intended to launch the concept of municipal ITE (Technical Inspection of Buildings) [2].

In the work "Rehabilitation of Buildings Methodology of Diagnosis and Intervention", it is proposed an exigencial evaluation of the performance of the constructive elements belonging to the external envelope of buildings, in order to create interior conditions of comfort. The referred document includes a computer application, called MEXREB. This software aims to facilitate the work of the evaluator and determine the degree of satisfaction of 21 requirements related to the envelope of buildings [3].

The method MANR (method of assessment of rehabilitation needs) proposed by LNEC (National Laboratory of Civil Engineering) allows the knowledge of the rehabilitation needs of a building to provide it with characteristics that ensure the satisfaction of the functional requirements at a level not inferior to the chosen one [4].

The methodology of inspection presented in the book "Gestão e Manutenção Preventiva de Bairros de Habitação Social Municipal" by the Department of Civil Engineering of the University of Aveiro was proposed and applied in the scope of preventive maintenance of housing stock [5]. 
Regarding dissertations already held on this subject, it's worth noting the dissertation prepared at the University of Beira Interior by Carlos Silva, titled "Rehabilitation of Multifamily Buildings of the 1950s and 1970s", which supported the present work in the methodology of inspection and evaluation [6]. It was also consulted the inspection records for buildings created by Marisa Monteiro, within the framework of her doctoral thesis under development at UBI, under the theme "Housing and health - methodology for risk assessment for occupants" [7]. Another important document that served as a basis for the structure, organization and elements for the present work was carried out at the University of Porto and proposes a methodology called "ITE for inspection of old buildings" and applies it to practical cases [8].

\subsection{Building Inspection Methodology}

The inspection methodology consists of a set of procedures supported by documents for the visual inspection and thermal analysis and measurements described below. The objective is to collect information about the building to intervene, since in the case of old buildings the respective projects are outdated and / or incomplete and often non-existent.

In the first phase a simple visual inspection was chosen, supported by an inspection form accompanied by a survey of residents. From these documents it is intended to carry out the survey of constructive elements, coatings, general infrastructures; evaluate the state of conservation and note all changes made over the years, since it is up to the residents' criteria / availability to intervene.

In addition to the creation of the documents previously described, it is essential to analyse the energy efficiency of these buildings, as they are not in accordance with current legislation, which causes high energy costs and can be reflected in monthly expenses, comfort and use of residents

\subsubsection{Inspection Form}

The first document to support methodology consists of an inspection form. The objective of this form is to evaluate the conservation status of the building (EC) from a scale of 1 to 4 , the extent of intervention (EI) that can be classified as: no need for intervention (SNI), located, medium and extensive and the lifting of materials, coatings, dimensions, 
among other parameters. There is also considered information related with general infrastructures, accessibility and fire safety. The inspection form is composed of:

1. General information and identification of the building;

2. External evaluation;

3. Evaluation of common areas and circulations;

4. Internal evaluation, which is subdivided into:

4.1. Internal evaluation;

4.2. Internal Evaluation - Circulations and hall;

4.3. Interior Evaluation - Kitchen;

4.4. Internal Evaluation - Sanitary Facilities;

4.5. Interior Evaluation - Rooms and Rooms;

4.6. Internal Evaluation - Other Locations.

\subsubsection{Residents Survey}

The second part of the evaluation methodology is characterized by the collection of information regarding the opinion of residents. The main objective of the survey was to collect information about the occupants/ user's profile and sensitivity regarding the knowledge of the problems that may arise in their dwelling specially related with use conditions. In addition, it is important to gather information on past interventions and interventions that are intended to be undertaken in the near future.

\subsubsection{Thermographic Analysis}

As studied building seems to have a weak thermal performance it was decided to complete the previous data collected with a set of continuous measurements, a set of thermograms and thermal analysis based on the actual Portuguese thermal legislation. Given the thermal, sustainability and comfort requirements of users it does not seem sufficient to delineate a rehabilitation intervention based on mere visual inspection and resident surveys, although these elements may give important indications. In order to complement the methodology, it was decided to perform a weekly thermographic analysis during two different periods of the day in the heating season. This technique was applied in the case of study in the periods referred as follows. 


\subsubsection{Continuous temperature and relative humidity measurements}

Following the thermographic analysis, the continuous measurements of temperature and relative humidity in the winter and summer seasons were performed and analysed. The data of measurements performed from May to July 2015 and from January to March 2016 were provided under Project 6.60.6 - Experimental Campaign [7], the values from July to September of 2016 were obtained in the other block of building in order to complement the information.

\subsubsection{Thermal analysis}

Finally, following the data collected and the architectural survey carried out during the inspection of the building, the calculations and the thermal analysis for each dwelling of the building were carried out according to the current Portuguese thermal legislation.

\section{Application to Case Study and Intervention Proposals}

\subsection{Case study}

The procedures and supporting documents described above were applied to a case study. It is a multifamily building from the 60's, located in the city of Covilhã (Figure 2), known as housing for economic income promoted by Caixa Sindical de Previdência. For the analysis of the information gathered the building was divided into the two parts of building served by common access.

\subsubsection{Inspection Form}

With the help of the inspection form, the survey was carried out in the common areas and circulations and in 12 apartments including the constructive elements of the envelope, main general infrastructures, accessibility and the conservation conditions. Through the residents' survey, occupancy and use data were collected in the same 12 apartments. The synthesis of information collected through the methodologies described above is available in the master's thesis entitled "Inspection and Rehabilitation of a multi-family building from the 60's in Covilhã" [1]. 


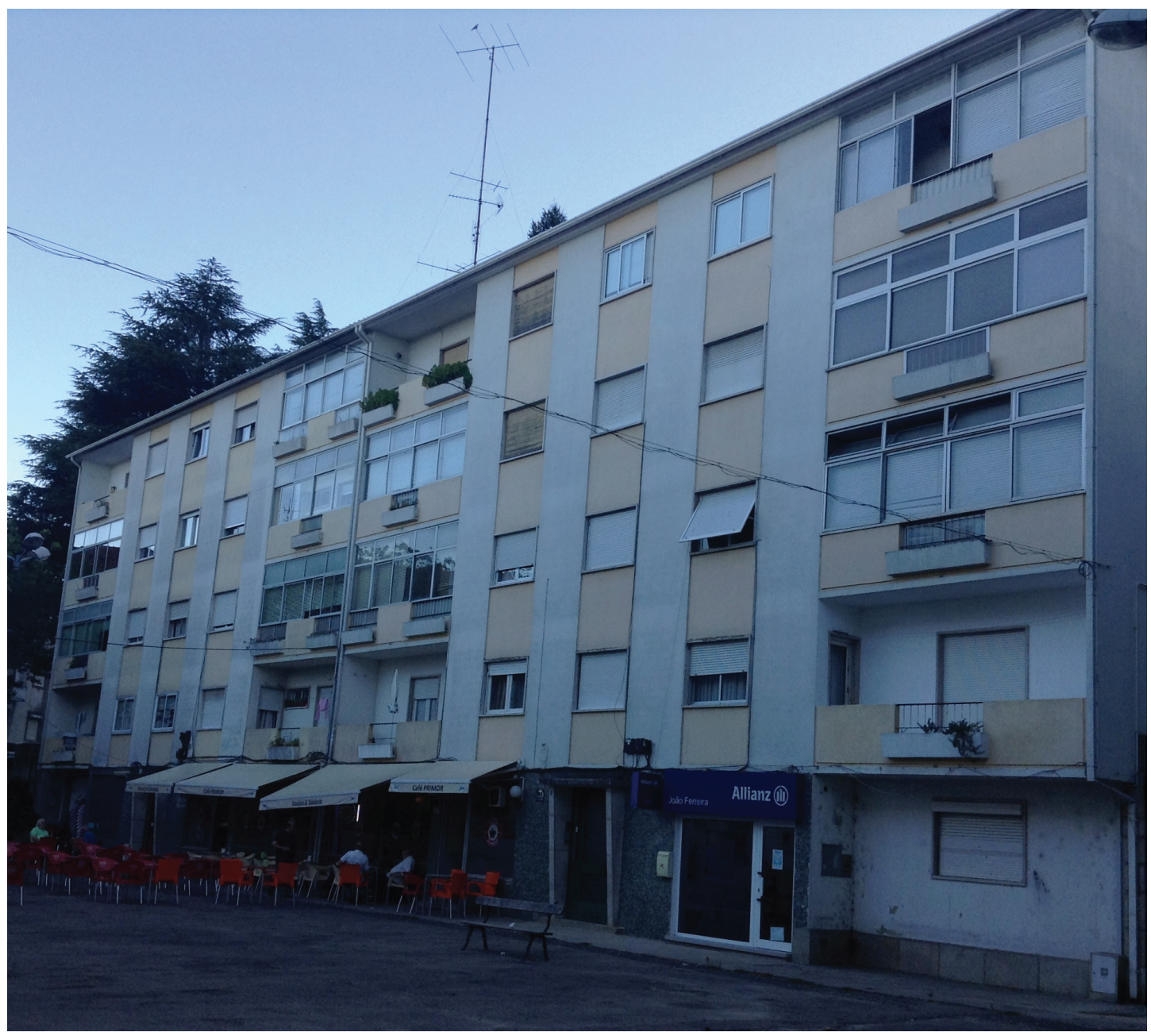

Figure 1: Case study - Multi-family building in Covilhã [1].

It could be concluded that the building under study has been poorly maintained over the years. Taking into account all the analysis performed, it is verified that the thermal discomfort is the most serious problem and that it is urgent to solve.

In a first approach, it was found that the infrastructures do not comply with the actual technical regulation. It was also found that all residents renovated the plumbing of water supply and changed the electrical panel recently.

The individual meters (water and electricity) exist, however, are located inside the dwelling which makes impossible the intervention of the concessionaires in case of damage.

As for the common facilities, in both parts of the building wastewaters collector was changed. It should be noted that gas installations have been recently completed in compliance with technical regulations. 
The telecommunication facilities do not comply in any way with the required technical regulations. In this way, there is a need to make a new reinstallation, in accordance with the legislation, for better operation and comfort of the users.

Since these are old apartments, accessibility conditions are not in accordance with the technical regulations, namely the lack of access ramp to the building, the dimensions of the stairs and handrail.

The most obvious anomalies related to the appearance are mostly associated with humidity and lack of maintenance.

In general, conservation conditions of the apartments are satisfactory, since residents who are almost entirely owners are careful to maintain and rehabilitate some compartments, namely kitchens and toilets. Nonetheless, those are the compartments with the worst classification, similar to the corridors and hall, due to the non-compliance of the general infrastructures. The fraction in worse state of conservation is property of the Municipality that according to the residents only solves serious problems of operation of general infrastructures.

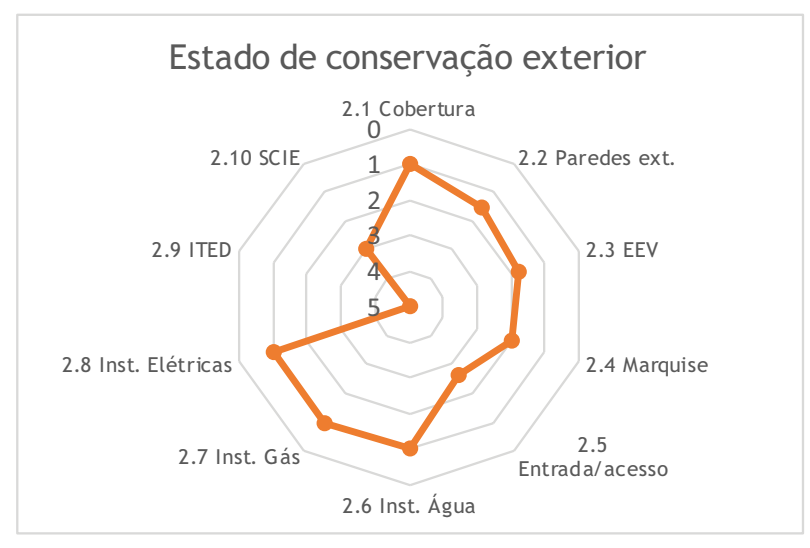

Figure 2: Example of conservation status graph [1].

According to the analysis of the inspection form, there is condensation, mainly in the kitchen and sanitary installations. The lack of ventilation is common to all apartments, so it is necessary to improve indoor air quality, so that the conditions of thermal insulation can be improved without creating further condensation.

\subsubsection{Residents Survey}

After the interviews, it was realized that the majority of the residents are over 61 years old. Most have resided in the building since its inauguration or have occupied it for the next five years. In this conversation, they were found to be dissatisfied with the thermal 
discomfort of the dwellings. However, they are also accommodated and not open to many changes, due to the inconvenience caused by the works, which can be explained by financial reasons. The occupants are dissatisfied with the secondary entrance due to its degradation. In part 1, the common areas and circulations have some anomalies at the level of the coatings that bothers residents. The use of heating equipment is avoided due to the high price of the electricity bill. The installation of the elevator, for the most part, would be a great help in the mobility inside the building, due to its age and difficulty of locomotion. Taking into account the entire inspection methodology used throughout this part of work, the intervention needs were identified in order to establish priorities.

\subsubsection{Thermography}

In the thermographic measurements several conditions for its realization arose. For this reason, the possible errors associated with climatic data (distance, humidity and wind speed) must be considered.

In the collected thermograms (Figure 3 ) the different temperatures in the envelope of building were observed. The main weaknesses, such as the flat thermal bridges (beams, pillars and shutters), the linear thermal bridges in the glazed spans and the cover slab, the sill and lintel were verified. As for the anomalies detected only "ghosts" were observed in the main façade.

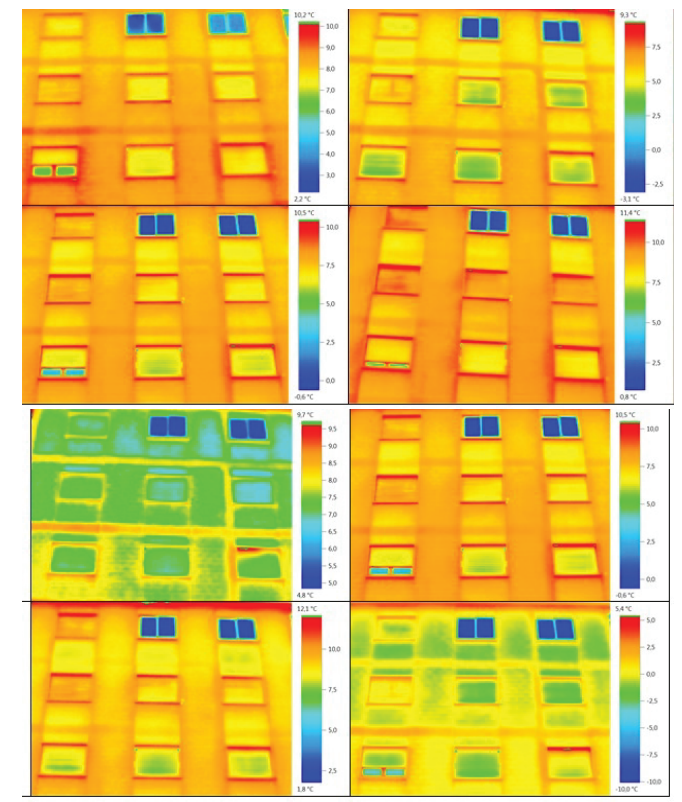

Figure 3: Examples of thermograms - Main façade [1]. 
It is important to note that the coffee has higher temperatures than the rest of the façade, which means that the ambient heating would be in operation. The rear façade is warmer when measured at night due to the use of the kitchen. Likewise, the toilet facilities are warmer when measured in the morning.

Some compartments of apartments are warmer than others, essentially at night, because the occupants only heat the most used ones. This is due to the fact that there are less residents than is assumed / admitted for each apartment typology. Through the thermography it was possible to check the apartments that are not occupied, in order to confirm the occupancy rate.

\subsubsection{Continuous Measurements}

In continuous measurements of temperature and relative humidity over different periods of time, it was concluded that in none of the apartments the temperature is between the stipulated values of $18^{\circ} \mathrm{C}$ for the winter and $24^{\circ} \mathrm{C}$ for the summer. Temperatures higher than $30^{\circ} \mathrm{C}$ were recorded in summer and less than $10^{\circ} \mathrm{C}$ in the winter inside. The relative humidity should be between $35 \%$ and $85 \%$. However, in the summer season, values were below $35 \%$ and winter values above $85 \%$. It is concluded that the conditions within the dwellings do not correspond to those required and cause discomfort for the occupants by confirming in practice the data obtained in the thermal calculation and the data collected in the surveys. At the attic 2 equipment were placed and verified greenhouse effect due to the large thermal amplitudes. The maximum temperature recorded corresponds to $45,9{ }^{\circ} \mathrm{C}$ in July and $12,4{ }^{\circ} \mathrm{C}$ of minimum in September.

\subsubsection{Thermal analysis}

From a technical point of view, calculations were made and energy certificates were created for all apartments and the respective energy classes shown in Fig. 4 were obtained.

In the case of the ground floor apartments, it was found that the energy class is similar, except for apartment G, as will be explained later. The value of the annual nominal primary energy needs (Ntc) is well above the reference value, hence the value of the ratio between them being very high. However, the value of the useful energy needs for cooling does not sometimes exceed the reference value. It should be noted that fraction $\mathrm{B}$, despite being geometrically identical to fraction $\mathrm{G}$, is in contact with ENU 
Figure 4: Energy classification of apartments (Main façade) [1].

(stairwell) and EU (T1 type apartment). On the contrary, the whole fraction $\mathrm{G}$ is in contact with two ENU (staircase and coffee collection) that do not have any type of insulation. As for dwellings of typology $\mathrm{T} 3$, similar values are verified, although the fraction $\mathrm{H}$ has slightly higher values. Intermediate fractions present lower values and similar values. It is evident that T3 apartments have smaller values, since they only have two façades in contact with the exterior, as opposed to the larger dwellings that have three. During the analysis, it was verified that the fractions that show marquise have advantage over balconies, because the atmospheric conditions abroad are more burdensome than in the ENU. Most of the useful energy requirements for cooling are below the reference value, with the exception of fraction I where the gross internal gains are higher than the reference gains in the heating season. The values of Nic, Nvc and Ntc of fractions D, I, K and $O$ are higher because their envelope is defined by the two types of wall (PRE1 and PRE2) and in turn, PRE2 has a coefficient of thermal transmission (2.15 W/ (m2.h)). As can be seen, the apartments in contact with the attic (Table 1) present the worst results.

It is a heavily ventilated attic without thermal insulation. The nominal global annual primary energy needs are much higher than the reference values in all apartments. In the case of Nvc, the values in fractions $E$ and $F$ are close, although they do not exceed the reference value. In fractions $L$ and $P$, the values are higher than the reference values. In $\mathrm{L}$, it is verified that the kitchen has been enlarged, so the type of wall present in the envelope is the one of smaller thickness (PRE2).

Comparing with the apartment $E$ that owns the same typology and that has balcony, the ratio between the global needs is higher. In P, in comparison to F, since they have the same typology, it was verified that the existence of a balcony exposes the fraction to the exterior, and besides, $\mathrm{F}$ has double windows. It should be noted that $\mathrm{E}$ has a smaller area than $\mathrm{F}$, but it has been found that it requires more energy, since in this case 
TABLE 1: Values of Mic, NVc, Ntc, Ntc / Nt and energetic classes of fractions located on the top floor [1].

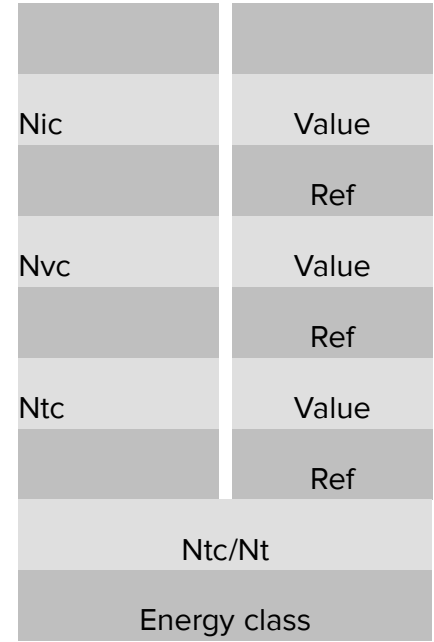

\begin{tabular}{|c|c|c|}
\hline E & F & L \\
\hline 246.65 & 229.60 & 259.59 \\
\hline 84.87 & 67.52 & 78.68 \\
\hline 12.91 & 12.17 & 14.73 \\
\hline & & 13.68 \\
\hline 326.61 & 684.59 & 761.21 \\
\hline 2.24 & 279.74 & 309.11 \\
\hline & 2.45 & 2.46 \\
\hline
\end{tabular}

\begin{tabular}{|c|}
\hline $\mathrm{P}$ \\
\hline 387.48 \\
\hline 98.84 \\
18.70 \\
\hline 1079.42 \\
\hline 358.15 \\
\hline 3.01 \\
\hline $\mathrm{F}$
\end{tabular}

the glazed component consists essentially of simple glass, frame and exterior wood protection and allows greater losses.

\subsection{Intervention proposals}

In this section it is intended to propose intervention solutions for the main problems existing in the building, having as priority to provide better thermal comfort to its occupants. By weighing the problems detected during the inspection, the opinions of the residents and the rest of the data collected, the priorities and the respective phasing of the intervention proposals were established. In the first phase, it is a priority to reinforce the insulation of building envelope, to change the glazed spans and their solar protections, to improve the ventilation and to implement the first phase of improvement of accessibility.

The second phase is to upgrade existing technical systems for sanitary water heating, implement new water supply facilities and reshape common areas and internal circulations.

In the third phase, it is intended to improve the ambient temperature and reduce the energy consumed by the users, by placing the heating equipment and solar collectors. The infrastructures to be altered correspond to the electrical and telecommunication installations, taking into account the power required for installation of elevator in the framework of common services.

The second phase of improvement of accessibilities corresponds to the installation of a lifting platform that is included in the fourth and last phase of intervention. 


\section{Conclusion}

In general, it was concluded:

- Given the time of construction, several factors such as economic, lack of knowledge and cost of living have dictated the option of less efficient solutions. Based on the 2011 Censuses, there are about 965,782 buildings in need of intervention.

- The case study building is outdated due to the construction period and lack of maintenance over the years;

- The inspection methodology was adapted to the multifamily building and at the time of study that could cover all buildings that are weak from a thermal point of view; in addition, the analysis of the collected data is easy to perceive and supports decision making in the informed intervention;

- Residents' opinions coincide with the technical perspective and the proposed phasing in of interventions;

- Phasing was thought cost-effective;

- The intervention proposals will turn the building more comfortable, healthy and safe;

- There is a need to sensitize residents to periodic maintenance of buildings and to the creation of mandatory inspections and rehabilitation funds in order to promote energy efficiency, health and accessibility of old buildings.

\section{Acknowledgments}

This work was partially financed by Portuguese national funds through FCT - Foundation for Science and Technology, IP, within the research unit C-MADE, Centre of Materials and Building Technologies (CIVE-Central Covilhã-4082), University of Beira Interior, Portugal.

\section{References}

[1] Inês I. G. Marcelino, "Inspeção e Reabilitação de um edifício multifamiliar da década de 60 em Covilhã". Dissertation of Master in Civil Engineering, FEUBI - Faculty of Engineering, University of Beira Interior, Covilhã, Portugal, 2017. (In Portuguese)

[2] Câmara Municipal de Lisboa - "ITE Inspeção técnica de edifícios", 2012. [Accessed in 09/01/2017]. Available online in http://www.cm-lisboa.pt/en/living-in/housing/ 
melhoria-da-qualidade-do-parque-habitacional/ite-inspeccao-tecnica-de-edificios

[3] João C.G. Lanzinha; "Reabilitação de edifícios - Metodologia de Diagnóstico e Intervenção", Digital book, Edition Fundação Nova Europa, Series Estudos de Engenharia, Volume 5, Support: University of Beira Interior, Covilhã, Portugal, ISBN 978-989-654-116-3, 2013. (In Portuguese)

[4] LNEC - Método de avaliação das necessidades de reabilitação. Desenvolvimento e aplicação experimental, Lisbon, Portugal (2011) (In Portuguese)

[5] Simões, A.; Costa, A.; Rodrigues, F.; Varum, H.; Matos, M. J.; Vicente, R. - Gestão e Manutenção preventiva de bairros de habitação social municipal, Aveiro, Edições Afrontamento (2015) (In Portuguese)

[6] Silva, Carlos S. N. - "Reabilitação de edifícios Multifamiliares das décadas 50,60 e 70", Dissertation of Master in Civil Engineering, FEUBI - Faculty of Engineering, University of Beira Interior, Covilhã, Portugal, 2013. (In Portuguese)

[7] Marisa Monteiro; Ana C.A. Sousa; M. Ramiro Pastorinho; João C. G. Lanzinha; Miguel Nepomuceno "Projeto 6.60.6 - Campanha experimental" in proceedings of ICEUBI2015 -International Conference on Engineering UBI2015 - "Engineering for Society"; ISBN 978-989-654-261-0 (Pendrive); Editor: UBI - Universidade da Beira Interior. Serviços Gráficos, Faculty of Engineering, University of Beira Interior, Covilhã - Portugal, 2-4 Dec 2015. (In Portuguese)

[8] Lanzinha, João N. F., "Inspeção Técnica de Edifícios Antigos”, Dissertation of Master in Civil Engineering, FEUP, University of Porto, Porto, Portugal, 2014. (In Portuguese) 